\title{
Interactive comment on "Yardangs and Dunes: Minimum- and Maximum-Dissipation Aeolian Landforms” by Ralph D. Lorenz
}

\section{Ralph Lorenz}

ralph.lorenz@jhuapl.edu

Received and published: 30 March 2020

It is gratifying that both reviewers Ozawa and \#2 consider the paper well-written and a good review of the topic. Neither of the reviewers challenges the thesis of the paper, that an analogy exists between the landforms formation in balanced (constructive/destructive - dunes) or unbalanced (constructive-only, fingering dunes or destructive-only, yardangs) settings and the emergence of maximum vs minimum dissipation (EP) states in thermodynamic systems.

Reviewer 2 calls for some more-or-less editorial changes, to sharpen the text and to elaborate some explanations and the specific contribution of this paper, as well as some minor figure fixes. 
Reviewer 2's suggestion to revise the title, to use 'versus' to underscore the contrast is a good one.

ESDD

Reviewer Ozawa points out some aspects which similarly need clarification, as ell as a couple of missing references.

Interactive comment on Earth Syst. Dynam. Discuss., https://doi.org/10.5194/esd-2019-73, teractive comment 2019. 